\title{
Experiencia brasileña con políticas de control del tabaquismo
}

Tania C avalcante, MD, MSP.(1)

B rasil es el país más grande de América del Sur, con un área de $8547403.5 \mathrm{~km}^{2}$ y una población de 169799170 habitantes. ${ }^{1}$ Está constituido por 26 estados y el Distrito Federal, Brasilia. Cada estado está dividido en municipios, y éstos son 5507 en todo el país.

Las principales causas de muerte en el país son las enfermedades cardiovasculares y el cáncer, cuyo más importante factor de riesgo es el consumo de tabaco. La mortalidad por cáncer pulmonar es la principal causa de muerte por cáncer para los hombres y la segunda para las mujeres; sin embargo, está aumentando más rápidamente entre estas últimas. Ya que entre 1979 y 1999 fue de $57 \%$ para los hombres y de $122 \%$ para las mujeres. ${ }^{2}$

Las cifras de muertes relacionadas con el tabaquismo en Brasil (80 000 muertes anuales en los años noventa y 200000 en la actualidad) ${ }^{3}$ llevaron al gobierno brasileño a adoptar medidas agresivas para controlarlo. A pesar de que Brasil es el tercer productor de tabaco del mundo y líder mundial en exportación de hojas de tabaco, el gobierno brasileño ha tenido éxito en desarrollar acciones fuertes y coordinadas para limitar el tabaquismo. ${ }^{4}$ A pesar de la fuerte inserción de la industria del tabaco en Brasil y de que la mayoría de los países en desarrollo ha experimentado un incremento en el consumo de tabaco, en Brasil, el consumo anual per cápita de cigarrillos ha bajado 32\% entre 1989 y $2002 .{ }^{5}$

No obstante, todavía existen enormes dificultades que deben enfrentarse, como el creciente consumo entre adolescentes y una más alta prevalencia de consumo de tabaco entre las muchachas. ${ }^{5}$ El hecho de que los cigarrillos brasileños estén entre los más baratos del mundo, ${ }^{6}$ aunado al fácil acceso y la disponibilidad de productos de precio aún más bajos provenientes del mercado negro, es un factor que facilita la experimentación y el consumo temprano de tabaco por parte de los menores de edad. $^{5}$

El mercado legal de cigarrillos de Brasil lo comparten básicamente dos grandes compañías tabacaleras: la compañía Souza Cruz, una subsidiaria de British American Tobacco (BAT), que controla $74 \%$ del mercado, y Philip Morris, que controla 13\%. Existen otras 14 pequeñas compañías tabacaleras que comparten el otro 13\% del mercado legal. ${ }^{7}$ Las dos más grandes compañías están interconectadas por un sistema global corporativo inteligente que las mantiene informadas sobre las tendencias del mercado del tabaco y sobre las políticas gubernamentales para su control en todo el mundo. Además, trabajan conjuntamente para construir respuestas globales eficaces a los retos que esas políticas representan para sus negocios. ${ }^{3,8} \mathrm{Al}$ igual que muchos otros países, Brasil ha sido blanco de esas estrategias y, a pesar de la firme legislación que existe en ese país para controlar el tabaquismo, las compañías tabacaleras frecuentemente han encontrado la manera de retarla; ello se debe a que suelen contratar a abogados expertos para hallar huecos en las disposiciones legales.

(1) Programa Nacional de Control de Tabaco, División de Control del Tabaco y 0 tros Factores de Riesgo de Cáncer. Instituto Nacional de Cáncer, Coordinación de Prevención yVigilancia. Ministerio de Salud. Brasil. Comité N acional para la Implementación del Convenio Marco para el Control del Tabaco en Brasil, Río de Janeiro, Brasil.

Fecha de recibido: 11 de mayo de 2004 - Fecha de aprobado: 3 de agosto de 2004 Solicitud de sobretiros: Dra. Tania Cavalcante. Rus des Inválidos 212, 20. andar - Centro- Rio de Janeiro -RJ, Brasil. Correo electrónico:taniac@ inca.gov.br, prevprim@ inca.gov.br 
Dichas compañías diseñan, asimismo, campañas y promociones sutiles destinadas a reducir el impacto de las medidas adoptadas por el gobierno. Por ejemplo, la reciente campaña de Souza Cruz Fume com moderaçao (Fume con moderación) promueve una marca de cigarrillos muy popular entre los jóvenes y trata de convencerlos de reducir su consumo. Esto representa una clara estrategia destinada a influir en la decisión de dejar de fumar transmitiendo la falsa idea de que es posible controlar la dependencia hacia el tabaco. Otras estrategias usan el argumento de que las acciones de control del tabaquismo generarán desempleo entre los cultivadores de tabaco y los trabajadores de la industria tabacalera.

\section{Programa brasileño de control del consumo de tabaco y sus objetivos}

Con el fin de articular las estrategias y los esfuerzos de diferentes grupos sociales, lo mismo gubernamentales que no gubernamentales, se ha partido de una óptica de promoción de la salud para controlar el consumo de tabaco. Desde 1989, el Instituto Nacional de Cáncer, (INCA) de Brasil, un organismo del Ministerio de Salud, coordina y articula las acciones del Programa Nacional de Control del Tabaquismo en todo el país.

El objetivo general de ese programa es reducir el consumo de tabaco y la prevalencia de fumadores, con el fin de bajar las tasas de morbilidad y mortalidad relacionadas con el tabaco en Brasil. Sus objetivos específicos son:

- Reducir la iniciación en el consumo de tabaco, especialmente entre los jóvenes.

- Reducir el acceso a los productos de tabaco.

- Brindar protección contra los riesgos de humo ambiental de tabaco.

- Reducir las barreras sociales que obstaculizan el dejar de fumar.

- Aumentar el acceso y la accesibilidad de tratamientos para dejar de fumar.

- Controlar y monitorear los productos tabacaleros en el país, desde su contenido y sus emisiones hasta sus estrategias de promoción y mercadotecnia.

- Monitorear y vigilar las tendencias de consumo, sus efectos en la salud, en la economía y en el ambiente, así como las estrategias de la industria.

\section{Estrategias}

Los objetivos arriba mencionados han servido de guía en el diseño de tres grupos estratégicos de acción; éstos a su vez conforman el marco que da sustentabili- dad a la expansión del Programa en el ámbito nacional. A partir de este marco estratégico se han construido importantes redes de colaboración para apoyar la articulación nacional y la ejecución de las estrategias centrales; entre estas últimas se incluyen las acciones educativas, la promoción para el abandono del consumo de tabaco y las medidas legislativas y económicas.

\section{Marco estratégico}

1. Articulación de una red nacional para descentralizar las acciones del programa. Considerando las dimensiones de Brasil y las dificultades que generan las diferencias regionales, culturales y económicas, así como el amplio rango de estrategias usadas por las compañías tabacaleras para aumentar el consumo de tabaco en todo el país, uno de los componentes vitales del Programa ha sido su proceso de descentralización, como consecuencia de los principios del Sistema Unico de Salud (SUS) de Brasil.

Esta acción articulada gracias a la participación directa de INCA incluye:

- La descentralización de la administración del Programa mediante el establecimiento y la articulación de una red de cooperación con las oficinas estatales y municipales de salud.

- La obtención de recursos financieros mediante acuerdos de trabajo con el Fondo Nacional de Salud del Ministerio de Salud y las Oficinas Estatales de Salud a partir de 1996.

- La articulación del Plan Nacional de Control del Tabaco con las oficinas de salud estatales y municipales para diseñar los planes locales de salud.

- La construcción de capacidades mediante la formación de recursos humanos dentro de las oficinas estatales y municipales de salud para la administración regional del programa y para multiplicar el proceso de descentralización en todos los municipios de cada estado.

Gracias al apoyo de esta red, el Plan Nacional de Control del Tabaco ha sido implementado en todo el país. Hoy día, 27 estados y más de 3600 municipios están trabajando en ella.

2. Promoción, articulación y monitoreo de las acciones intersectoriales para el control del tabaco. Con el fin de fijar una posición durante las negociaciones internacionales para el establecimiento del Convenio Marco para el Control del Tabaco (CMCT), el 
presidente de Brasil firmó un decreto en 1999 por el cual se creó una estructura gubernamental multisectorial, el Comité Nacional de Control del Tabaco, que dio al Programa de Control del Tabaco el estatus de un programa gubernamental.

Correspondió a este comité evaluar los datos e información nacionales sobre el tema y asesorar al Presidente en la definición de la postura que debía mantener el país durante el proceso de integración del CMCT entre 1999 y 2003. El Comité Nacional estaba presidido por el Ministro de Salud, y el INCA llevaba la Secretaría Ejecutiva; asimismo, participaban en él delegados de los ministerios de Salud; Relaciones Exteriores; Agricultura; Economía; Justicia; Trabajo; Educación; Desarrollo, Industria y Comercio Exterior, y Desarrollo Agrario.

En agosto de 2003 un nuevo decreto presidencial remplazó a ese organismo con el Comité Nacional para la Implementación del Convenio sobre el Control del Tabaco y sus Protocolos, un organismo permanente que hasta la fecha incluye delegados de 11 ministerios del gobierno. El carácter consultivo del antiguo comité fue remplazado por la naturaleza ejecutiva del nuevo, lo cual mostró que el gobierno brasileño está preparando una base de apoyo nacional para responder a las diversas obligaciones impuestas por el CMCT, el cual signó y pretende ratificar.

Como en el anterior, el Ministro de Salud preside el nuevo Comité, y el INCA funciona como su secretariado ejecutivo, responsable de articular sus actividades. El nuevo Comité inicio su agenda de trabajo elaborando un documento que analizaba el mercado brasileño de cigarrillos, la política fiscal correspondiente así como la recomendación de incrementar los impuestos y precios de los cigarrillos. Como resultado de ello, en diciembre de 2003, el gobierno aumentó dichos impuestos en $20 \%$.

3. Construcción de redes de colaboración y alianzas con la sociedad civil organizada para propagar y movilizar el apoyo social al control del tabaco. El Programa ha establecido redes de colaboración con organizaciones no gubernamentales, sociedades científicas, asociaciones de profesionales de la salud y la educación y otros actores sociales interesados en el control del tabaco. Estas redes han sido esenciales para ampliar el alcance de las acciones educativas del Programa y fortalecer el control social enfocado en el apoyo al Programa en contra de las acciones de la industria del tabaco.

\section{Estrategias centrales}

1. Acciones de educación a la comunidad. Las acciones educativas se dirigen a diferentes grupos con los siguientes objetivos:

- Socializar el conocimiento científico y difundir información sobre los daños provocados por el tabaco, los beneficios que aporta dejar de fumar, las maneras de hacer esto último, las estrategias de la industria que promueven el hábito de fumar y la legislación para el control del tabaco en Brasil.

- Movilizar el apoyo de toda la sociedad y de los líderes de opinión.

- Estimular cambios de opinión y de actitud entre los líderes de opinión.

Estas acciones educativas consisten en campañas anuales para el control del tabaco, como el Día Mundial sin Tabaco (31 de mayo) y el Día Nacional contra el Hábito de Fumar (29 de agosto), coordinadas por el Ministerio de Salud y el INCA.

Otras acciones incluyen la difusión de información en los medios, para conseguir el apoyo de éstos al Programa. Obtener la confianza y la simpatía de los medios implicó la generación de datos para llamar su atención, la organización de conferencias de prensa con información confiable y la preparación de un equipo de personas para comunicarse con ellos, especialmente durante la discusión de aspectos conflictivos. Este proceso convirtió al INCA en referencia nacional para los medios en cuanto a control del tabaco y permitió conseguir el apoyo de éstos en todo el país para la difusión de acciones y hechos en favor de dicho control.

Al reconocer que la información por sí sola no necesariamente lleva a cambios en el comportamiento, el Programa también ha incluido intervenciones sociales y ambientales destinadas a desencadenar cambios positivos en el comportamiento una vez que el conocimiento se difunde. Para alcanzar este objetivo se escogieron tres canales comunitarios: lugares de trabajo, escuelas y unidades de atención a la salud. Esas intervenciones permitieron la articulación de acciones educativas continuas en las que la difusión de información sobre los riesgos de fumar -especialmente de fumar pasivamente- suele ir a la par con la restricción de fumar en ciertos ambientes cerrados y la promoción del abandono del tabaco. 
Gracias al apoyo de la red de descentralización en los estados y municipios, en 2002, el Programa Nacional había llegado a 1102 compañías y otros lugares de trabajo, 7709 escuelas y 2864 unidades de atención a la salud. Ese mismo año, más de 2198 municipios celebraron al menos una campaña anual sobre control de tabaco.

Con el fin de motivar las iniciativas nacionales sobre control del tabaco, una vez al año el INCA promueve una premiación en la cual estados, ciudades, compañías, centros de atención a la salud, escuelas, organizaciones no gubernamentales e individuos son nominados para recibir reconocimientos por su labor sobresaliente en la implantación de acciones para el control del tabaco.

2. Acciones para promover y apoyar el abandono del hábito tabáquico. Para motivar a los fumadores a que dejen de fumar y aumentar su acceso a métodos basados en evidencia para lograrlo, se han articulado varias medidas diferentes y complementarias:

- Difusión de información en los medios y en eventos relacionados con la salud, sobre métodos eficaces para dejar de fumar y realización de campañas.

- Capacitar a los profesionales de la salud en intervenciones de apoyo para el abandono del hábito tabáquico y en el tratamiento de la dependencia al tabaco.

- Implantación de una línea telefónica gratuita de ayuda (Marque Dejar de Fumar).

- Inclusión de métodos eficaces para dejar de fumar, en la atención rutinaria a la salud dentro de los servicios provistos por el SUS.

- Articulación de una red de salud pública con el fin de mejorar el acceso al tratamiento para dejar de fumar.

- Mapeo y difusión de información para que la gente pueda encontrar apoyo para dejar de fumar dentro del sistema público de atención a la salud.

Producto de lo anterior, en agosto de 2000, el INCA llevó a cabo la Primera Reunión de Consenso sobre el Tratamiento para Dejar de Fumar con la participación de miembros selectos de consejos profesionales de salud, y asociaciones y sociedades científicas relacionadas con la salud, con el fin de generar recomendaciones para el tratamiento de los fumadores en Brasil. Esa reunión generó el documento Abordagem e tratamento do fumante. Consenso
(Abordaje y tratamiento del fumador. Consenso), publicado en 2001 y que se ha difundido entre los profesionales de la salud en todo Brasil.

El INCA brindó apoyo técnico al equipo de Marque Dejar de Fumar (cuyo número se encuentra impreso en los paquetes de productos de tabaco junto a las nuevas advertencias del Ministerio de Salud), organizó el banco de datos del sistema y entrenó a los profesionales de la salud que trabajan en Marque Dejar de Fumar.

Se dio entrenamiento intensivo a profesionales de la salud de 276 instalaciones públicas de salud sobre atención al fumador e implantación de clínicas de pacientes ambulatorios para fumadores dentro de la red pública (54 de estas instalaciones públicas ya están dando atención gratuita para dejar de fumar). Este proceso empezó en septiembre de 2001, y su meta es llegar al menos a 300 centros públicos de atención a la salud de los fumadores para finales de 2004.

Entre las acciones pagadas por el SUS, en agosto de 2002 se publicó la resolución del Ministerio de Salud que incluye las pautas a seguir en el tratamiento para dejar de fumar (abordaje del comportamiento cognitivo y terapia de remplazo de la nicotina, así como administración de buproprion).

3. Movilización y articulación de políticas y medidas tanto legislativas como económicas que favorecen el control del tabaquismo. Muchas de las acciones para controlar el consumo de tabaco basadas en evidencia recomendadas por la Organización Mundial de la Salud (OMS) están fuera del ámbito de acción de los ministerios de salud, ${ }^{9}$ pues implican medidas legislativas y económicas.

En este contexto, es importante poner de relieve las leyes necesarias para: garantizar a la población el acceso a información acerca de los riesgos del consumo de tabaco; reglamentar los productos de tabaco en cuanto a sus contenidos y emisiones; proteger a la población de la exposición a humo ambiental de tabaco; proteger a los jóvenes de la inducción al consumo de tabaco propiciada por la publicidad, la promoción y el patrocinio de las compañías tabacaleras, y facilitar el acceso al apoyo terapéutico para dejar de fumar. Por otra parte, también es necesario imponer medidas que dificulten el acceso de los jóvenes a los productos de tabaco, como el incremento de los impuestos y precios, al igual que el control de las ventas y, especialmente, del mercado ilegal de tabaco.

Las acciones educativas y las medidas económicas y legislativas se complementan entre sí. Los 
antecedentes legislativos han servido para realzar y reforzar las medidas educativas desarrolladas por el Programa. Al mismo tiempo, las medidas educativas crean una red de apoyo para asegurar y estimular la implantación de las medidas legislativas y económicas para el control del tabaco.

A pesar de que el Ministerio de Salud no tiene un poder directo de decisión ni de ejecución sobre muchas de estas medidas, sí ha trabajado para movilizar y cabildear acciones legislativas y económicas. Dado que, desde la Secretaría Ejecutiva del Comité, lleva 15 años desarrollando y coordinando acciones del Programa Nacional de Control del Tabaquismo, en todo el país, el INCA se ha convertido en la referencia fundamental para obtener asesoría técnica en los procesos legislativos y pronunciamientos. Esto le ha permitido hacer avanzar las medidas legislativas y económicas.

Por su parte, la red del Programa Nacional de Control del Tabaquismo también ha jugado un importante papel en el cabildeo y el apoyo a los legisladores para la creación y la aprobación de leyes que favorecen el control del tabaco, al tiempo que la evolución de la legislación brasileña en este sentido ha significado un apoyo importante para el desarrollo de acciones educativas por parte del Programa.

a) Regulación de los productos de tabaco. En 1995, el INCA dio un paso fundamental en la realización de acciones reguladoras de los productos de tabaco al patrocinar una evaluación de los contenidos tóxicos de cinco de las más conocidas marcas brasileñas de cigarrillos.

En 1996, a partir de la gran difusión que se hizo en los medios de esa evaluación, cuyos resultados demostraron que las concentraciones de sustancias tóxicas en muchos de los cigarrillos analizados estaban muy por arriba del máximo establecido en otros países, el INCA defendió públicamente la necesidad de reglamentar los contenidos y emisiones de los cigarrillos brasileños. Al mismo tiempo, el INCA lanzó un documento en el que se listaba una serie de recomendaciones al gobierno para el establecimiento de reglamentaciones legislativas que obligaran a los fabricantes o importadores de cigarrillos a hacer del conocimiento del Ministerio de Salud todos los contenidos de sus productos e imprimir esa información en los paquetes de los mismos. También daba recomendaciones para establecer la metodolo- gía de análisis, así como las reglamentaciones y los procedimientos de inspección. Esto último propició la puesta en marcha de la reglamentación, el control y la inspección de cigarrillos, puros y cualquier otro tipo de productos de tabaco para fumar, con la intervención de la Agencia Nacional de Vigilancia Sanitaria (ANVISA), creada por una ley federal en enero de $1999 .{ }^{10}$ A través de este organismo, el Ministerio de Salud obtuvo el poder para regular y controlar los productos de tabaco en cuanto a sus contenidos, emisiones, promoción, embalaje y etiquetamiento. Muchos otros avances fueron posibles en este campo, tales como:

- La limitación de los niveles máximos de alquitrán, nicotina y monóxido de carbono, los cuales deberán ser de 10 mg, 1 mg y $10 \mathrm{mg}$, respectivamente, para los cigarrillos vendidos en Brasil.

- La prohibición del uso de clasificaciones en las marcas, como "light", "ultralight", "suaves" y similares, que pueden transmitir al consumidor la falsa idea de que son productos menos dañinos.

- La obligación de imprimir en uno de los lados de los paquetes de cigarrillos la siguiente frase: “Este producto produce más de 4700 sustancias tóxicas y contiene nicotina, la cual causa dependencia física y psicológica. No existe ningún nivel seguro para el consumo de estas sustancias".

- La definición de las características gráficas de las advertencias sobre salud y de las fotos que aparecen en los paquetes de los productos.

- La obligación de las compañías tabacaleras de hacer un registro anual y un informe periódico de los productos que mercantilizan, incluyendo información sobre las ventas y características fisicoquímicas de los mismos. Esta resolución impone una cuota de registro (30 000 dólares) anuales para cada marca vendida en Brasil, aunque las compañías la están cuestionando en la corte.

- Luego de la prohibición del uso de descripciones como "light" y "suave", el Ministerio de Salud, a través de ANVISA, también prohibió el uso de números o nombres de colores relacionados con los nombres de las marcas, método que había sido usado para conservar una comu- 
nicación subliminal con los consumidores respecto al carácter "light" y menos dañino de ciertas marcas.

En este proceso, el papel del INCA ha sido:

- Proveer del conocimiento técnico a ANVISA en lo que se refiere a las medidas reguladoras de los productos de tabaco.

- Estructurar un banco de datos (SISTAB) para almacenar la información que los productores o importadores de tabaco deben entregar a ANVISA en relación con los productos que venden en Brasil.

- Dar apoyo técnico a ANVISA, con el fin de corroborar la precisión de la información entregada por los fabricantes de productos de tabaco.

b) Prohibición de la publicidad y la promoción de tabaco. La publicidad y la promoción de los productos de tabaco funcionan como un poderoso estímulo social para empezar a fumar, así como para mantener y aumentar la dependencia del tabaco; y también crean dificultades sociales para el proceso de dejar de fumar y sostener la abstinencia de tabaco. Hoy en día existen numerosas evidencias que justifican la prohibición total de publicidad y promoción como parte de un programa para el control del tabaco. ${ }^{11}$ Incluso los documentos internos de la industria del tabaco muestran claramente cuáles son los verdaderos objetivos de esas actividades y su eficacia.,

Estos antecedentes llevaron al Ministerio de Salud brasileño a desplegar acciones legislativas para prohibir los anuncios y la promoción de productos de tabaco. En el año 2000, como Secretaría Ejecutiva del Comité Nacional para el Control de Tabaco, el INCA impulsó al gobierno brasileño con el fin de que presentara una ley para prohibir totalmente la publicidad y la promoción del tabaco. Al mismo tiempo, con la colaboración de la red para el control de tabaco en los estados y municipios, propició el apoyo de la sociedad civil a esta ley difundiendo información sobre los daños causados por el tabaco y sobre la influencia de la publicidad y la promoción en el incremento del consumo de tabaco.

A pesar de la fuerte alianza opositora que construyeron las compañías de tabaco y las asociaciones de televisión, radio, carreras de autos, cultivadores de tabaco y otros para tratar de impedir la medida, el proyecto se convirtió en ley federal en diciembre de 2000, de tal manera que quedó prohibida la publicidad de productos de tabaco en televisión, radio, revistas, periódicos y calles. No obstante, el argumento de que la Constitución brasileña no permite la prohibición total de publicidad para un producto legal fue esgrimido por dicha alianza para que se permitiera anunciar el tabaco en los espacios interiores de los lugares de venta, como hasta hoy sucede.

Más adelante se lograron otros avances como la prohibición de la publicidad para tabaco por medios electrónicos, pues la industria tabacalera empezó a utilizar la Internet como punto de venta y, al mismo tiempo, de publicidad. Con el fin de contrarrestar esta estrategia, el Ministerio de Salud hizo una enmienda a la ley mediante una resolución de ANVISA, en la que se definen los puntos de venta y se aclara que la Internet no lo es.

Esta ley también prohibió a las marcas de tabaco promover eventos culturales y deportivos a partir de enero de 2003, con la excepción de eventos deportivos internacionales, pero sólo hasta septiembre de 2005. Por otra parte, cualquier transmisión de eventos internacionales promovidos por productos de tabaco debe incluir una contrapublicidad antes y después de la transmisión, y durante las transmisiones deben aparecer cada 15 minutos advertencias, tanto escritas como verbales, sobre los daños a la salud que provoca fumar. ${ }^{12}$

c) Impresión de fuertes advertencias sobre riesgos para la salud y del número de la línea telefónica para dejar de fumar, sobre los paquetes de productos de tabaco que han sido cuidadosamente diseñados para atraer a los fumadores por sus colores, formas y los nombres de las marcas. Su objetivo también es mostrar mensajes subliminales para tranquilizar a los fumadores acerca de los daños que causa fumar. ${ }^{13-15}$ Así, el hecho de que aparezcan en las cajetillas fuertes advertencias sobre la salud desempeña un importante papel para contrarrestar esta sutil estrategia mercadotécnica.

Los documentos internos de la industria del tabaco muestran con claridad las diferentes estrategias usadas a los largo de los años para asociar ciertos colores de los paquetes con la idea de productos "ligeros" y para promo- 
verlos como alternativas seguras e inteligentes, en vez de desalentar el hábito de fumar. ${ }^{16}$

Todos los documentos de la industria tabacalera también reconocen que estas estrategias de mercadotecnia tienen más éxito gracias a la dependencia que produce la nicotina y crean una fuerte relación entre los fumadores y los empaques de sus marcas preferidas. ${ }^{17}$ Además, estudios de comportamiento sobre la dependencia hacia el tabaco muestran que los paquetes de cigarrillos siempre están presentes en la vida del fumador, en situaciones de placer y satisfacción al igual que en momentos de tristeza y conflictos. Muchas veces el fumador enciende un cigarrillo por reflejo, y muchas claves sociales, como beber café, leer, realizar un trabajo intelectual, conducir y otras, funcionan como detonadores del reflejo. ${ }^{18,19}$

Estos estudios también muestran que las intervenciones en conducta cognitiva se encuentran entre los métodos para dejar de fumar cuya eficacia está basada en evidencia. ${ }^{20-22}$ De este modo, el proceso de obtener conocimiento acerca de los riesgos del consumo de tabaco y el rompimiento del hábito automático de encender un cigarrillo, en asociación con la promoción de cambios en el comportamiento mediante métodos que mejoren la eficacia personal para lidiar con los componentes psicológicos de la dependencia hacia el cigarrillo, son el núcleo del proceso de dejar de fumar. En este contexto, obtener información sobre los riesgos de fumar y sus dimensiones es uno de los primeros pasos en el proceso.

Otro elemento que puede contribuir a romper con la conducta automática de fumar, consiste en crear obstáculos que dificulten el acceso a los paquetes de cigarrillos u otro tipo de barreras. Así que, además de reforzar entre los fumadores el conocimiento sobre la dimensión del riesgo de fumar, fuertes advertencias sobre ello en los paquetes, en especial cuando están ilustradas con imágenes, también pueden romper con la atracción y los detonadores que llevan a encender un cigarrillo en diferentes situaciones durante el día.

Otra función importante de esta medida es cambiar las creencias culturales positivas acerca del hábito de fumar. En este contexto, es importante entender que las creencias individuales y culturales acerca del efecto de una droga psicoactiva son determinantes mayores de la propagación de su uso en una sociedad. Uno de los factores más importantes de la representación social del uso de una droga es el contexto social y la influencia del ambiente sobre los efectos esperados. ${ }^{23}$

En Brasil, desde 1988, se han usado los empaques de tabaco como medio para informar a la sociedad sobre los daños causados por el tabaco. En ese año se implantó la primera medida respecto a las advertencias sobre los efectos del tabaco con un mensaje único: "El Ministerio de Salud advierte: fumar es dañino para su salud". A lo largo de los años esa medida se volvió cada vez más fuerte. En 1995, el Reglamento Interministerial 477 modificó ese mensaje con una más variada y directa serie de advertencias sobre los riesgos para la salud que implica fumar. Esa nueva regulación estaba firmada por el Ministerio de Salud, el Ministerio de Comunicación y el Ministerio de Justicia, además de ser resultado de un proceso de negociación entre estos tres ministerios y asociaciones representantes de la industria del tabaco y el sector publicitario.

En 2001, una medida provisional firmada por el presidente de Brasil determinó que las advertencias sobre la salud en las cajetillas tendrían que ilustrarse con imágenes. Al mismo tiempo, una resolución de ANVISA se encargó de definir cómo debían ser estas últimas.

Otra resolución de ANVISA fue la que prohibió a la industria tabacalera el uso de descripciones de los productos tales como "light" (ligero), suave, bajo contenido u otros términos que pueden dar una falsa idea de seguridad del producto. También fue la que obligó a las compañías a poner información en los paquetes acerca de los contenidos de nicotina, alquitrán y monóxido de carbono, así como una advertencia adicional: "No existe ningún nivel seguro para el consumo de estas sustancias".

Tal resolución también obligó a las compañías a insertar el número de la línea telefónica de ayuda para dejar de fumar (Marque Dejar de Fumar) en los paquetes. En esa línea telefónica la gente puede obtener consejos y orientación sobre cómo dejar de fumar, y recibe mensajes que apoyan y realzan su eficacia personal para lograrlo. La línea telefónica tiene localizados los servicios de la red nacional de apoyo para dejar de fumar y orienta a 
los fumadores sobre los lugares en donde pueden obtener una atención más intensiva para lograrlo.

En febrero de 2002 empezaron a circular los primeros paquetes con las nuevas advertencias sobre riesgos para la salud. Así, una encuesta llevada a cabo por el Instituto Datafolha en abril de 2002 entre más de 2000 personas en 126 ciudades brasileñas, mostró que $76 \%$ de ellas aprobaban la medida; $73 \%$ de los fumadores la aprobaban, y $67 \%$ dijeron que las imágenes aumentaban su intención de dejar de fumar. Por otra parte, luego de la difusión del número telefónico de Marque Dejar de Fumar en los paquetes, la cantidad de llamadas se incrementó en 300\%.

Estos hallazgos concuerdan con los de una encuesta realizada por el equipo de trabajo de esa línea telefónica entre marzo y diciembre de 2002. Esa encuesta incluyó a 89305 personas, $80 \%$ de las cuales eran fumadores. Del universo entrevistado, $92 \%$ aprobó la medida, $79 \%$ dijo que las fotos de las advertencias deberían ser más impactantes y $90 \%$ dijo haberse enterado de la línea telefónica a través de los paquetes. Tomando en cuenta que estos datos sugerían que la población esperaba que las imágenes de las advertencias fueran todavía más impactantes, que debe difundirse mucha más información sobre los daños causados por el tabaco y que es necesario renovar periódicamente las imágenes y las advertencias-dado que tienden a perder su fuerza inicial-, el Ministerio de Salud dispuso otra medida destinada a remplazar las advertencias con otras aún más impactantes a partir de julio de 2004 (figura 1).

También se remplazó la información cuantitativa, con la siguiente frase en letras blancas sobre fondo negro en una de las caras laterales de los paquetes: "Este producto produce más de 4700 sustancias tóxicas y contiene nicotina, la cual causa dependencia física y psicológica. No existe ningún nivel seguro para el consumo de estas sustancias". Además, se prohiben mensajes tales como "sólo para adultos" o "producto para mayores de 18 años" y otros que las compañías solían incluir "voluntariamente" en la otra cara lateral de los empaques. Esta nueva regulación obliga a las compañías tabacaleras a remplazar ese mensaje "voluntario" por uno nuevo dirigido a los vendedores de tabaco: "Venta prohibida a menores de 18 años - Ley 8.069/ 1990. PENADA con 6 meses a 2 años de prisión y multas".

4. Vigilancia y monitoreo. Brasil carece de datos actualizados sobre las tendencias del consumo de tabaco, que permitan evaluar las acciones del
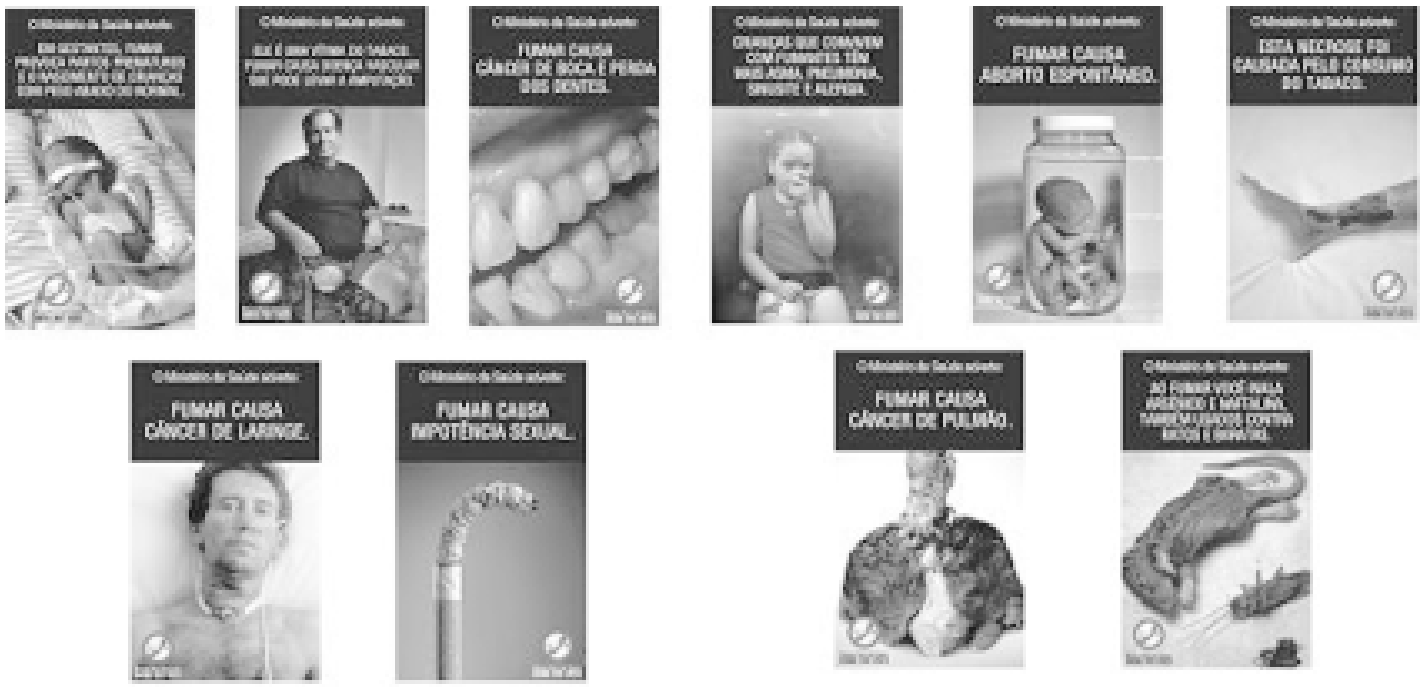

Figura 1. Advertencias ilustradas con fotografías sobre los daños que fumar produce en la salud, y Que APARECEN IMPRESAS SObRE LAS CAJETILLAS DE CIGARROS A PARTIR DE JULIO DE 2004, EN BraSIL. 
Programa. Debido a ello, el INCA está estructurando un sistema de vigilancia para el control del tabaco en todos sus aspectos. De este modo, se ha recopilado información de distintas fuentes y se están realizando investigaciones y encuestas al respecto. También se ha apoyado la elaboración de estudios que evalúan o mejoran el desarrollo de nueva tecnología para el Programa o que mejoran la operación de este último.

\section{Algunos resultados}

De acuerdo con la Encuesta Nacional de Salud y Nutrición de 1989, la prevalencia de fumadores mayores de 15 años en Brasil era de 32.6\%. En 2003, la prevalencia de tabaquismo en la población de más de 15 años fue de 19\%, según la Encuesta Nacional de Hogares sobre Conductas de Riesgo y Morbilidad Referida Relacionada con Enfermedades no Transmisibles y Lesiones, llevada a cabo por el Instituto Nacional de Cáncer y la Secretaría de Vigilancia Epidemiológica del Ministerio de Salud, en 16 capitales de Brasil.

En 2001, una encuesta en Río de Janeiro desarrollada por el INCA, en colaboración con la Johns Hopkins University, mostró una prevalencia de 21\% (en 1989, ésta era de 30\%). El descenso en la prevalencia de fumadores fue más importante para los grupos de edad de 20 a 24 años (29\% en 1989 y $12 \%$ en 2001) y de 25 a 34 años (de $41 \%$ a 18\%). Esta encuesta también mostró que la reducción en la prevalencia entre los hombres fue mayor que entre las mujeres. ${ }^{24}$

Asimismo, el consumo anual de cigarrillos per cápita ha descendido de manera significativa. Entre 1980 y 2002, dicho consumo (de los mercados legal e ilegal) bajó 38\%, es decir, de 1937 a 1160 unidades.

\section{Consideraciones finales}

El control del tabaco en Brasil ha alcanzado importantes avances durante los últimos 15 años. Vale la pena resaltar tres pasos decisivos dentro de ese proceso. El primero se relaciona con el papel del INCA como coordinador del Programa Nacional de Control del Tabaquismo y su iniciativa de construir una red de colaboración que ha sido alimentada y motivada por la continua interacción. La actividad del INCA ha sentado una base suficientemente sólida para crear una conciencia nacional sobre los daños que causa fumar e impulsar la legislación para el control del tabaco.

El segundo paso está relacionado con la posibilidad de reglamentar los contenidos, emisiones, etiquetación y actividades de promoción de los productos de tabaco, gracias al papel de ANVISA como controlador e inspector de los productos de tabaco.

El tercer paso tiene que ver con la creación de un mecanismo multisectorial para el control del tabaco, el Comité Nacional para la Implementación del Convenio sobre el Control del Tabaco y sus protocolos, el cual ha contribuido a alcanzar numerosos avances intersectoriales y ha dado mayor visibilidad y poder político al Programa al convertirlo en un programa gubernamental.

Por otro lado, a pesar de los diversos avances y de algunos resultados positivos en el control del tabaco, todavía existen muchos retos que deberán enfrentarse:

1. Los datos nacionales muestran que las muchachas están fumando más que los muchachos y sugieren que a las mujeres se les dificulta más dejar de fumar.

2. Los cigarrillos brasileños están entre los más baratos del mundo.

3. La legislación que prohibe fumar en lugares cerrados, no se aplica completamente.

4. Las compañías tabacaleras continúan buscando huecos en la legislación que limita el consumo y la comercialización de sus productos.

5. A pesar de que los fumadores brasileños están entre los más motivados del mundo para dejar de fumar, ${ }^{25}$ el acceso al apoyo terapéutico y al tratamiento para dejar de fumar todavía es limitado, si se consideran las dimensiones del país.

6. Pocos profesionales de la salud reciben entrenamiento de pregrado para apoyar y tratar la adicción a la nicotina.

7. A pesar de la legislación que prohibe la venta de cigarrillos a menores de edad, muchos se las arreglan para comprarlos, ya sea en el mercado legal o en el ilegal.

8. Las compañías de tabaco están desarrollando estrategias para facilitar el acceso a los cigarrillos, tales como la venta a través de máquinas expendedoras.

9. Brasil fue el segundo país en firmar el CMCT, pero existe oposición para ratificar este convenio, entre legisladores que cabildean en favor de las compañías tabacaleras.

10. En su papel de uno de los mayores fabricantes de tabaco del mundo, Brasil necesita encontrar soluciones para los impactos negativos que en el futuro pueda tener el control global del tabaco sobre esa actividad económica, especialmente sobre la etapa de cultivo (la más vulnerable de la producción de tabaco). 


\section{Referencias}

1. Instituto Brasileiro de G eografia e Estatística, 2000. Censo 2000. Rio de Janeiro: Instituto Brasileiro de G eografia e Estatistica. D isponible en : http:/ /www.ibge.gov.br. [10-09-2003]

2. Ministério da Saúde / Instituto Nacional de Cáncer. Estimativas da incidencia e mortalidade por câncer no Brasil,2002. Rio de Janeiro: Instituto N acional de Cáncer; 2002.

3. Pan American Health O rganization. Health in the A mericas, 2002. W ashington, DC: PAH $0 ; 2002$.

4. A merican Cancer Society. Luther Terry awards leadership on tobacco control - Helsinki, 2003. Atlanta (GA):AC S; 2003.

5. Ministério da Saúde / Instituto N acional de Câncer - Programa N acional de Controle do Tabagismo e 0 utros Fatores de Risco de Cáncer - Modelo Lógico e A valiaçao, 2003. Rio de Janeiro: IN G; 2003.

6. Guidon E,Tobin D,Yach D. Trends and affordability of cigarettes prices: Ample room for tax increases and related health gains. Tob Control 2002;11:35-43.

7. Ministério da Saúde / Instituto N acional de Cáncer (IN CA) - Por um mundo livre de tabaco. - Açao G lobal para C ontrole do Tabaco:10Tratado Internacional de Saúde Pública. 2a edición, Rio de Janeiro: IN C;2003.

8. Campaign for Tobacco Free Kids \& Action on Smoking and Health (Ash). Confíe en nosotros. Somos la industria tabacalera.W ashington, DC: $\mathrm{N}$ ational Center for Tobacco Free Kids; 2001.

9. World Health $O$ rganization. Confronting the tobacco epidemic in an era of trade liberalization. Ginebra: W H $0 ; 2001$. (W HO /N MH/TFI/01.4, 2001).

10.A gencia N acional deVigilancia Sanitaria. D erivados delTabaco/legislación. Rio de Janeiro:Agência N acional deVigilância Sanitaria. D isponible en:http:/ /www.anvisa.gov.br. [2003 septiembre 10].

11. World Bank. Curbing the epidemic. Governments and the economics of tobacco control.W ashington, DC: Banco Mundial; 1999.

12. Ministério da Saúde / Instituto N acional de Cáncer (IN CA). Legislaçao Federal sobre Tabaco no Brasil, atualizado em agosto de 2003. Rio de Janeiro: IN C A; 2003. D isponible en: http://www.inca.gov.br/tabaqismo/ 13. Kozlowski LT, Pilliteri JL. Beliefs about "light" and "ultra light" cigarettes and efforts to change those beliefs:A n overview of early efforts and published research.Tob Control 2001;10 Suppl 1:S4-S11.

14. Pollay RW, Dewhirst T. Marketing cigarettes with low machinemeasured yields. En: Shopland DR, Burns DM, Benowitz N L, Amacher
RH, ed. Smoking and tobacco control. Risks associated with smoking cigarettes with low machine- measured yields of tar and nicotine. Bethesda (MD): $\mathrm{N}$ ational Institutes of $\mathrm{H}$ ealth, $\mathrm{N}$ ational $\mathrm{C}$ ancer Institute; 2001:199-235. (Monograph 13).

15. Shiffman S, Pilitteri JL, Burton SL et al. Smoker's beliefs about "Light" and "Ultra Light" cigarettes.Tob Control 2001;10 Suppl 1: Si17-Si23.

16. Koten J. Tobacco marketer's success formula: Make cigarets [sic] in smoker's own image.The W all Street Journal 1980 febrero 29:22.

17. Spears A. Re cost of making tobacco products. Lorillard 1973 noviembre 13.

18. Henningfield JE, Cohen C, Pickworth W B. Psychopharmacology of nicotine. En: 0 rleans CT, Slade J, comp. N icotine addiction. Principles and management. N uevaYork (N Y): 0 xford University Press; 1993.

19. Balfour DJ,Fagerström KO . Pharmacology of nicotine and its therapeutic use in smoking cessation and neurodegenerative disorders. Pharmacol Ther 1996;72(1):1-30.

20.0 rleans $C T$, GlynnTJ, Manley MW, Slade J.Minimal-contact quit smoking strategies for medical settings. En: 0 rleans CT, Slade J, comp. Nicotine addiction. Principles and management. $\mathrm{N}$ uevaYork (N Y): 0 xford University Press; 1993.

21. Fiore MC, Bailey W C, C ohen SJ, D orfman SF, Goldstein MG, G ritz ER et al. Smoking cessation. Smoking Cessation Guideline Panel. En: C linical Practice G uideline. Rockville (MD):U.S. D epartment of H ealth and Human Services, Public Health Service,A gency for Health C are Policy and Research; 1996. (N umber 18, A HCPR Publication no 96-06292).

22. Fiore MC, Bailey W C, C ohen SJ, D orfman SF, Goldstein MG, G ritz ER et al.Treating tobacco use and dependence. En:C linical Practice Guideline. Rockville (MD): U. S. D epartment of Health and Human Services, Public Health Service,A gency for Heath Care Policy and Research; 2000.

23. Marlatt GA. Prevenção da recaída: racionalidade teórica e visão geral do modelo. En: Marlalt, Gordon, ed. Prevenção de recaída: estratégias de manutenção no tratamento de comportamentos adictivos. Porto Alegre: Artes Médicas Sul; 1993.

24. Figueiredo VC, Szklo M, Szklo AS, Lozana JA, Casado L, Masson E et al. Smoking prevalence in a random sample of the population aged 15 years and older living in Rio de Janeiro, Brazil, 2001.12th.W orld C onference on Tobacco or Health; 2003 agosto 3-8; Helsinki, Finland.

25. G igliotti A P. Hábitos, atitudes e crenças de fumantes em quatro capitais brasileiras: uma comparação com 17 países europeus (tesis). São Paulo: Escola Paulista de Medicina; 2002. 